\title{
Effect of scattering extinction coefficient on drying rate
}

\author{
M. A. Akintunde \\ Department of Mechanical Engineering. Federal University of Technology, Akure. \\ P. M. B. 704 Ondo State, Nigeria, ajyinka@yahoo.com \\ ABSTRACT
}

Drying is purposely meant for preservation at lowest possible cost. The methods of drying can be categorized into two broad headings - Natural and Artificial. In the natural drying method, solar radiation is the major factor required. It has been observed that less than $30 \%$ of the radiation from the sun actually reaches the earth surface, the rest are reflected or scattered by the particles of the media through which it passes. As human activities on the earth surface increase, more panicles are released into the atmosphere and hence the rate at which the solar radiation is scattered (or extinct) is at increase. The rate at which the solar radiation reaching the earth surface is scattered was hypothetically measured by drying moist produce in a semi-closed solar drier. The evaporated moisture (forming smog) from the produce was used as the hypothetical atmospheric particles. The effect of this radiation scattering (scattering extinction coefficient, or kvalue) on the drying rate was observed. It was noted that the k-value increases as the amount of particles are increased, and this led to a decrease in drying rate. It was adjudged that, has more particles are released into the atmosphere more radiation will be scattered and drying rate of produce will be reduced. This effect is not known at present due to the general global warming resulting from ozone depletion.

Keywords: Solar radiation, Drying Rate, Scattering, k-value, smog, moisture

\section{INTRODUCTION}

There are many methods of drying (especially of fresh Agricultural produce) these methods can be grouped under two broad headings - Natural and Artificial,[9]. The natural method is basically thedrying in the sunlight, whether directly (i.e. spreading in an open space) or indirectly (by harnessing solar energy for drying purposes). While the artificial method includes, using of steam, electricity, coal and such like for drying purposes.

If preservation of texture, nutrient and other vitamins at minimum possible cost is of important, natural method of drying is invaluable, but if drying time and the period of preservation is to be considered artificial method comes to play [1]. On the other hand solar energy is pollution free and renewable, hence the natural means is prefer to artificial means of drying.

The quest for harnessing and proper utilization of renewable energy sources - principal actor for natural drying - is so topical from the late $20^{\text {th }}$ century, [2], [3] and [10], because of the imminent depletion of fossil

fuels (e.g. oil. gas and coal) principal actor for artificial drying- that the whole scientific world is avid with researches into means of tapping, harnessing and maximum utilization of the huge amount of energy from the sun apparently wasting away.

On the other hand, sustainable development has been defined as: "providing for a secure and satisfying material future for everyone in a society that is equitably, caring and attentive to basic human needs", [4]. Berman and Brazel [6] put his own definition of sustainable development as "the state in which the consumption of naturally endowed resources, social and economic access are of such levels that they can be sustained into the indefinite future without causing great or irreparable harm to future generations of people throughout the world". From these definitions and allusions, it can be affirmed that for sustainable development and environmental protection points of view, natural mode of drying is by far the best; since it has no negative effect on plants, animals and environment at large and it cannot be depleted.

Judging from the available literature, the amount of solar radiation (or solar energy) reaching the earth surface continue to dwindle as a result of increasing human activities, [10]; and [8]. This is caused by the way the light is scattered by various media it passes through before reaching the earth surface. The way in which light is scattered by various media has been 
a source of interest and investigation for many years. The scientific basis for today's understanding of the phenomenon began essentially in 1871 with the work of J. W. Strutt (Lord Rayleigh) who used Maxwells theories of electromagnetism to interpret Tyndall's observations on scattering of white light by small dust particles and to explain why the sky is blue and the light from it plane polarized.

Among the direct benefits descended from this work are a number of useful methods of investigating the properties and nature of macromolecules and extremely small particles or colloids. Static Light Scattering (SLS) techniques, in which the time averaged intensity of the scattered light is measured, are capable of yielding information on particles which are very- small compared with the wavelength of the incident light but are now more frequently used in the determination of polymer properties such as molecular weight, [9]. The newer techniques of Dynamic Light Scattering (DLS) extract information from the very short-term fluctuations in the intensity of the scattered light to give information on the dynamics of particles or macromolecules; such methods are popularly used to estimate particle sizes in the submicron range. Hence this work intends to investigate how the scattering of light radiation affects the rate of drying of agricultural produce and to present the effective way of utilizing available solar energy for drying processes taking into cognizance the effects of scattering extinction coefficient.

For particles which are small compared with the wavelength of the light, the radiation intensity is uniform in all directions and is proportional to the sixth power of the particle diameter. This is referred to as Rayleigh scattering. For particles whose size is comparable with the wavelength of the light, the scattered intensity is angle dependent. Some of the theories used in the measurement of scattering of light are illustrated in section 2.0 of this article.

Scattering Theory: Solar radiation emanating from the sun is attenuated by atmospheric constituents (aerosol and gases) before reaching the ground. As a result, maximum radiation on the earth is received under cloudless and clear skies [4], [7]. Sunlight is attenuated by at least $30 \%$ during its passage through the earth's atmosphere. The attenuation model as presented by [7] is presented in equation (1).

$$
I_{\lambda}=I_{0 \lambda} \cdot e^{-\mu}
$$

where: $\mu=\kappa l$; I is the optical path length. $\mathrm{K}$ is the monochromatic extinction or attenuation coefficient; $\mu$ is the monochromatic extinction optical thickness; $I_{0 A}$ is the total solar radiation; and $I_{\lambda}$ is the fraction of total radiation reaching the earth's surface.

This solar attenuation $(\mathrm{K})$ is due to some factors. These are highlighted below:

Rayleigh Scattering (or Scattering by molecules in the Atmosphere): Rayleigh scattering theory was based on the assumption that "the scattering particles are spherical with diameter, $\mathrm{d}$, much less than the wavelength $(\lambda)$ of the incident light radiation". This diameter, $d$, has been proved to be in the range " $d<$ $0.2 \lambda$ " [7], [10]. The degree of attenuation by the theory was found to be strongly dependent on the number of particles per unit volume and the refractive index of the particles; in the path of the radiation. Raylegh's equation that describe light scattering quantitatively is presented in equation (2).

$s=24 \pi^{3}\left(\frac{n^{2}-1}{n^{2}+2}\right) \frac{V^{2}}{4 \lambda}$

where: $s$ is the total amount of light of wavelength $(\lambda)$ scattered by a sphere of volume (V) and refractive index (n) per unit intensity of illumination. The relationship between $\mathrm{K}$ and $\mathrm{s}$ is given in equation (3)

$\kappa=\frac{s}{V} I_{\lambda}$

Absorption by Atmosphere and its Constituents: Solar radiation is also attenuated by the atmosphere and its constituent's gases e.g. Oxygen, Ozone, Water vapour and Carbon(IV)-oxide in particular. The relationship between total scattering extinction coefficient (St) (which is the sum of the scattering extinctions coefficient of the Rayleigh gas (k) and fine particle (Sf)) and the visual range (Lv) is provided by the empirical equation (4) presented by [9].

$$
L_{v}=\frac{3.912}{s t}=\frac{3.912}{k+s f}
$$

Mie Scattering: This is the Scattering due to aerosols and dust particles. Mie equation (5) predicted the nature of light scattered under this condition. This equation is applicable when the particle in question is comparable in size or larger relative to the wavelength of the incident radiation; then the scattered light was assumed to be the result of light wave originated from various parts of the particle. 
$k=\frac{2}{n^{2}} \sum_{v=1}^{\infty}\left(\frac{a_{v}^{2}+\rho_{v}^{2}}{2 v+1}\right)$

where: the refractive index $(n)$ is given by: $n=\frac{2 \pi r r}{\lambda}$ and $a_{v}=\frac{2 \pi r n}{\lambda}$ also $\rho_{v}=\frac{2 \cdot \pi \cdot r n}{\lambda^{2}}=\frac{a v}{\lambda}$ $r$ is the particle radius, $\lambda$ is the wavelength, $v$ is the particle volume and $\mathrm{k}$ is the scattering coefficient.

Hence, if $s$ is defined as the scattering per unit crosssectional area of the particle the relationship between $s$ and $k$ is given in equation (6).

$S=k \pi r^{2}$

\section{MATERIALS AND METHODS}

The experimental set up consists of a mix-mode solar dryer design for the drying of agricultural produce by [1]. The mixed mode consists of two boxes - inner and outer boxes- between these two boxes were lagging materials to prevent excessive heat lost. The boxes were exposed at the top to direct sunlight in this experiment. On the base of the inner box of the rig were fitted ten mass sensor probes which were connected to digital mass spectrometer. The mass spectrometer measures between $5 \mathrm{~g}$ to $50 \mathrm{~g}$, with a resolution of $\pm 0.01 \mathrm{~g}$. On these sensors were placed ten trays of moist cacao beans spread to be dried. Each tray contains $25 \mathrm{~g}$ of wet produce. The solar radiation reaching the surface of the test rig was taken as the direct radiation while the radiation measured at the surface of the sample scattered by the moisture from the produce was taken as the scattered radiation. Both the direct and the scattered radiations were measured by Kipps Solarimeter, model SL-56, with resolution of $2 \mathrm{~W}$. Normally when moist produce (such as cacao) is dried, evaporated moisture usually form miasma or smog above the drying produce at certain distance depend on the moisture content of the produce, [2]. The location of the smog was identified by the use of temperature/humidity meter. This meter indicates high humidity and low temperature when it is placed below the smog, when the meter is above the smog high temperature and low humidity will be indicated. It should be noted that the distance between the smog and the surface of the drying sample is not constant so also is the thickness of the smog, both depend on the moisture content of the sample and the solar radiation intensity, [3]. The following parameters were measured and recorded: the direct and scattered radiations; lost in weight of the sample and the internal (or drying) temperature at regular intervals of two hours. A rough estimate of the smog thickness/intensity was made, with the help of temperature humidity meter, an average value was recorded. The average value of the measured weight was used to compute the drying rate per hour. Data acquisition was terminated after six days when the weights of the samples appear to be constant.

\section{RESULTS AND DISCUSSIONS}

The measured values of direct $\left(I_{\circ \lambda}\right)$ and scattered $\left(I_{\lambda}\right)$ radiation was used to estimate the value of $(\mu)$ from equation (1). It should be noted the $\left(\mathrm{I}_{\mathrm{o}}\right)$ is the solar radiation reaching the rig while $\left(I_{\lambda}\right)$ is the one scattered by the smog. The smog was taken as the atmospheric particles scattering the incident radiation. Taken the particle diameter as 0.21 [7] and a unit wave length. The refractive index (n) was estimated to be 0.629 using $n=\frac{2 \pi r r}{\lambda}$ from equation (5), this in consonant 1.52 used by [2]. The values of (s) and (k) were estimated using equations (2) and (4) respectively.

The values of $k$ from equations 3 to 5 follow the same trend, these are shown in Fig. I and the trend equations are shown in Fig. 2. Fig. 3 shows the drying rate and the average drying rate for the six days. Fig. 4 shows average drying (or internal) temperature of the experimental rig, while Fig. 5 gives the average smog thickness per day.

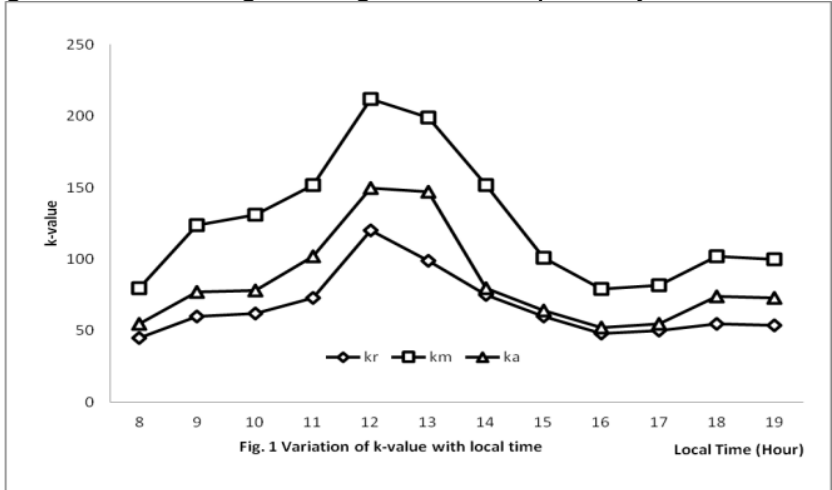

As could be observed in Fig. 1, the k-values from equations (3) to (5) which are for Rayleigh, Absorption and Mie Scatterings respectively follow the same trend. The trend line (relative to the local time) and the correlation coefficients for the three kvalues are shown in Fig.2. Figs. 2 to 4 show that as the average temperature increases so also the kvalues and the drying rate until around noon. Since higher $k$-value is an indication of less energy availability for the drying, the increasing in the drying rate must be due to increasing and higher-level of 
temperature during this period. After the noon period, there is a general fall in the k-values as well as the temperature, while the drying rate kept increasing. At this period, the k-value is low and hence more energy is available for the drying but at low temperature. More so the rig used is an insulated box which conserves energy, these explain the increasing trend noticed in the drying rate.
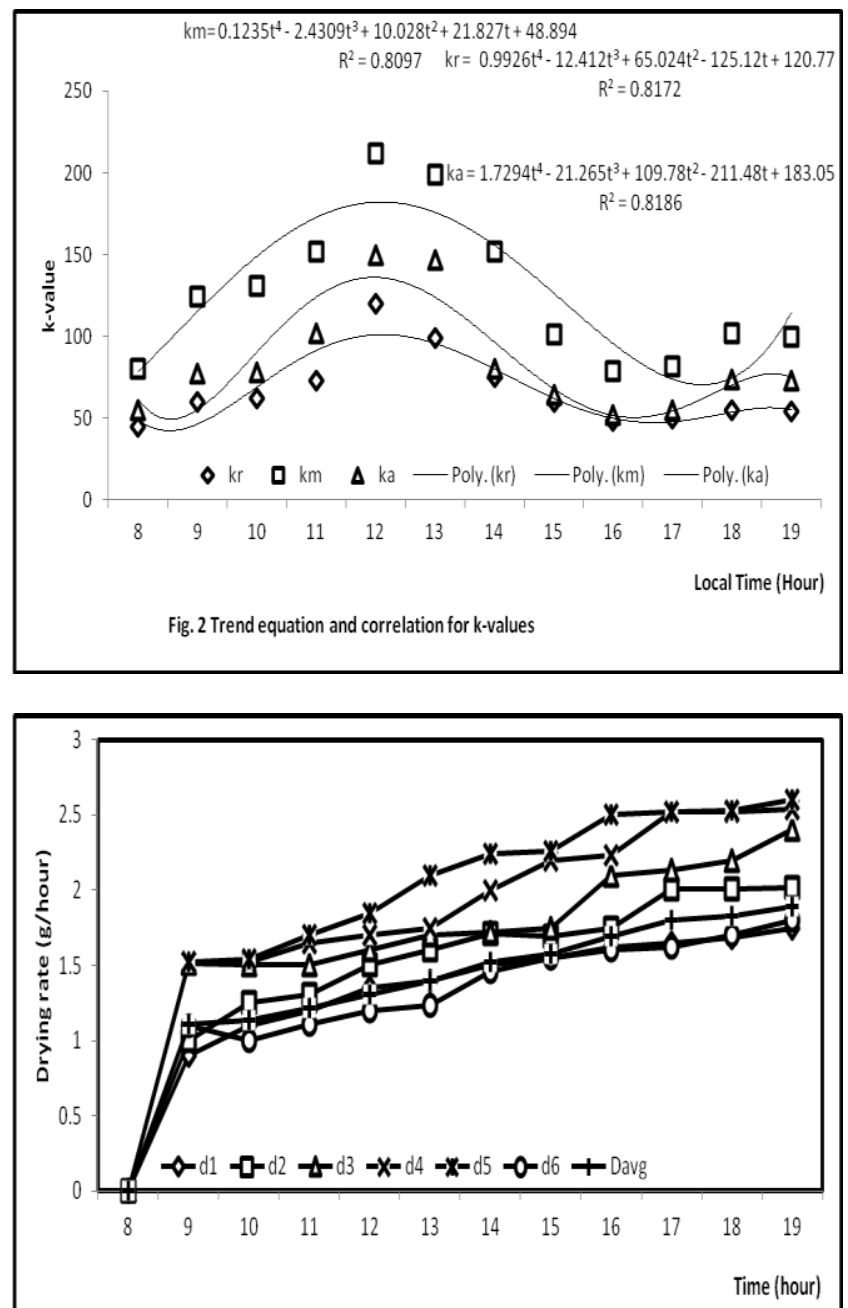

Fig. 3 Variation of drying rate with local time

In Fig. 3, it can be observed that the drying rate increases from day-one (d1) to day-five (d5). As the produce continues to dry the moisture content reduces. As a result the thickness or the intensity of the formed smog reduces (Fig. 5). Due to this, the incident radiation was less scattered, resulting in more energy available for the drying purpose.
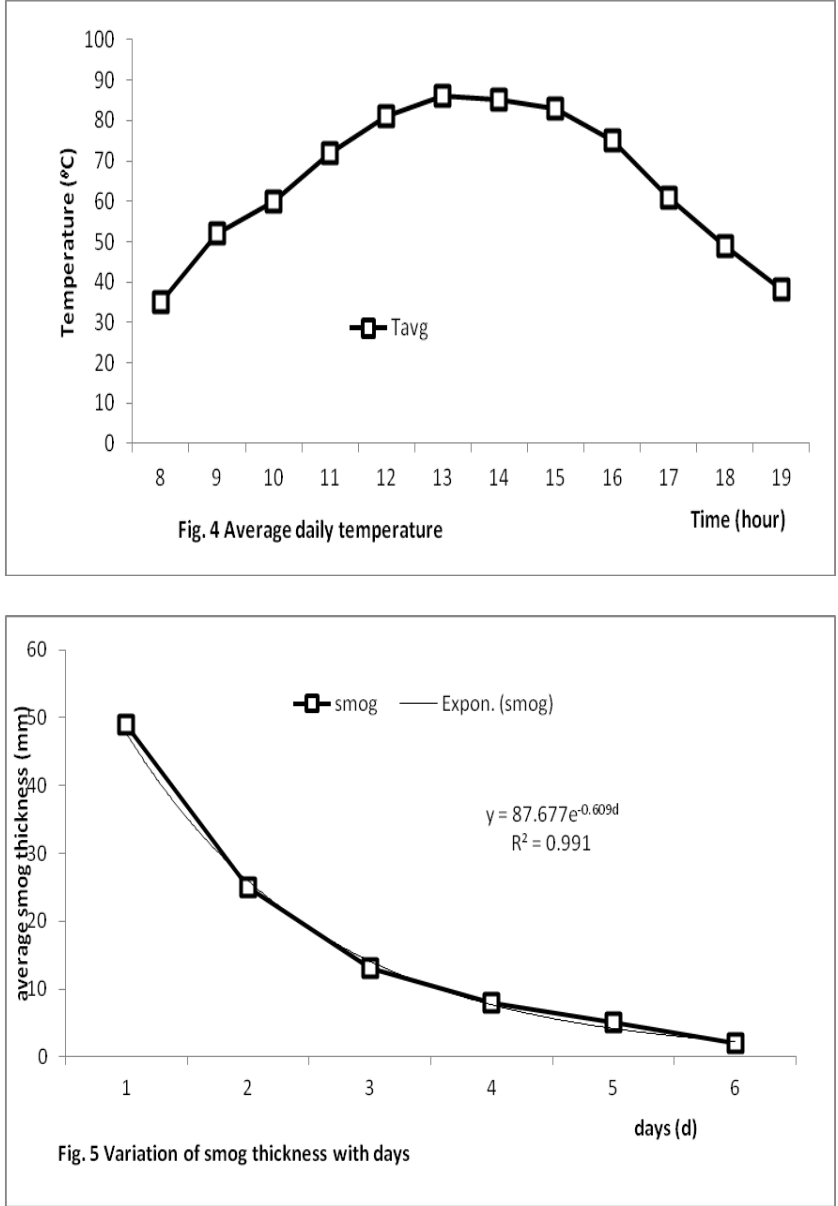

It is clear that the more the radiation is scattered the higher the $\mathrm{k}$-value and the less is the available energy for drying. As human activities increases and more particles are introduce into the atmosphere, the effectiveness of solar radiation for drying and other purposes will continue to dwindle. The reason why this is not noticed at present may be due to the depletion of global ozone which has resulted into general global warming.

\section{CONCLUSION}

From the obtained results, three separate relationships were used to determine the Scattering Extinction Coefficient ( $k$-value). These relations give the same pattern of the k-value variation with the local time and indicated same correlation coefficients $\left(R^{2}\right)$. The k-values increase with the amount of available particles scattering the solar radiation. This in turn reduces the amount of available energy for drying purpose. Since drying rate is a function of available energy (in form of heat), it would be expected that as more radiation is scattered less heat 
energy (or temperature) would be available for drying and hence a reduction in the drying rate. It was noted that the drying rate kept on increasing on the daily basis. This was due to available temperature resulting from the global warming effect and the energy conservation ability of the experimental rig.

It is clear that as drying continues, moisture content of the produce reduces and less smog is available to scatter the solar radiation (Fig. 5). Judging from the observed drying rate. (dl to d5, Fig. 3), which increases at an average rate of $12.5 \%$ per day, shows that the less the radiation is scattered the more is the drying rate. It can then be concluded that, as more particles are introduced into the atmosphere less energy will be available for drying and other purposes. The effect will be severe if the global warming is effectually stopped

\section{REFERENCES}

Akinola, A.O. (2004), "Development of a Mix-mode Solar Drier" M.Eng. Thesis, in the department of Mechanical Engineering, Federal University, Akure.

Akintunde, M. A. (1997), "Development of Solar Hot Box Cookers". Unpublished M.Eng. Project. The Federal University fo Technology, Akure. Department of Mechanical Engineering.

Akintunde, M. A. (1998), Performance Evaluation of Solar Hot Box Cookers in Akure. Journal of Applied Science; Vol. 2 No: 1 pp $380-393$
Amadi, R. U. Muokebe, I. S.O. and Okeke, C. E. (1986), "Measurement of Scattering Extinction Coefficient of Atmospheric Fine Particles at Nsukka". Nigerian Journal of Solar Energy. Vol. 5, pp 50 - 60

Owonubi, J. J. and Olorunju, S. A. S. (1986), "Solar Radiation Measurements and Energy Balance of Crops in the Nigerian Savanna". Nigerian Journal of Solar Energy. Vol. 5, pp 61-65.

Litman, T. (2001), "Exploring the Paradigm Shifts Needed to Reconcile Transportation and Sustainability Objectives". Transportation Research record. No. 1670, pp 8 - 12.

Sambo, A. S; and Doyle, M.D.C. (1986), "Estimation of the Global and Diffuse Components of Solar Radiation for some Nigerian Cities". Nigerian Journal of Solar Energy. Vol. 5, pp 16-24.

Berman, N.S. and Brazel, A. J. (2002), "PM-10 Air Quality in Ambos Nogales". South-West Center for Environmental Research and Policy. Vol. 2 No: 2, pp $71-79$

Akintunde, M. A. (1997), "Development of Solar Hot Box Cookers". " M.Eng. Thesis, in the department of Mechanical Engineering. Federal University, Akure

McMulan, J. T. (2002), "Refrigeration and Environment Issue and Strategies for the Future". International Journal of Refrigeration. Vol. 25.No: 1, pp 89 - 99

Ogunlowo, A.S. and Olalusi, A. P. (2000), "Simulation of Cocoa Beans Drying". Journal of Engineering and Engineering Technology. Vol. 2 No 2. pp 6 - 10.

Bolaji, B. O. (2005), "Development and performance evaluation of a Box-type Absorber Solar Air Collector for Crop Drying". Journal of Engineering and Applied Science. Vol.1 No: I.pp 1-8. 